\title{
Preparation of Quality Control Material for Assuring Quality of Electrical Conductivity Measurements in Soil
}

\author{
Ibrahim F. Tahoun*, Randa N. Yamani and Adel B. Shehata \\ National Institute of Standards, Tersa St, El-Matbah, Haram, P. O. Box: 136, Code \\ No: 12211 Giza, Egypt.
}

\begin{abstract}
A CCURATE and reliable analytical results of soil have become essential tool for understanding salinity and limiting factors affecting agricultural productivity. Reliability of results depends mainly on the existence and quality of reference materials which are considered as crucial tools for validation and verification of the analytical process and assuring quality of measurement results. The National Metrology Institute of Egypt [NIS] is striving to set up the national standards to ensure all measurement results are traceable to the international system of unit (SI). NIS starting development of a series of soil reference materials to meet Egyptian requirements and customer demands. This article describes the production process of the soil reference material characterized for electrical conductivity from processing to value assignment. Characterization, homogeneity and stability studies of the material were carried out according to ISO guides 34,35 and 80 . The measurement results were statistically analyzed to calculate assigned values. The assigned value and expanded uncertainty for $\mathrm{EC}_{1: 1}$ and $\mathrm{EC}_{1: 5}$ methods were found $1234 \pm 58 \mu \mathrm{S} / \mathrm{cm}$ and $973 \pm 52 \mu \mathrm{S} / \mathrm{cm}$, respectively.
\end{abstract}

Keywords: Electrical Conductivity, Soil, Quality Assurance, Secondary reference material.

\section{Introduction}

Electrical conductivity (EC) of a soil extract is the most widely used parameter for describing soil salinity and concentration of dissolved mineral salts present in the soil [1]. Electrical conductivity estimates the concentration of ions in the soil, and consists predominately of the cations $\mathrm{Na}^{+}, \mathrm{Ca}^{+2}, \mathrm{~K}^{+}$, and $\mathrm{Mg}^{+2}$ and the anions $\mathrm{Cl}^{-}, \mathrm{SO}^{-2}$ and $\mathrm{HCO}_{3}^{-}[2,3]$. Salinity is one of the most severe environmental factors limiting the productivity of agricultural crops. Until the 1950 's, the salt contents of soils were estimated from the electrical conductivity of saturated soil pastes. As a result of progress made in the understanding of saline soils, it was found that the plant responds to the salt concentration of soil solution rather than the total salt content of the soil. Therefore, the conductivity of the saturation extract is recommended as a general method for estimating soil salinity in relation to plant growth $[1,4]$. Extract based on soil to water ratios of $1: 1$, $1: 2,1: 2.5,1: 5$, and $1: 10$ are commonly used to determine the EC values of soils but ratios of $1: 1$ and 1:5 are mainly used by routine and ISO/IEC 17025 accredited testing laboratories applying standard methods for consistent determination of
EC of a soil [1, 5-6]. The result of EC depends on shaking, stirring, agitation, equilibration times, centrifuging, or filtration procedures that have been used to prepare extracts. The aim of this research work was to prepare a reference material from soil characterized for EC to be used in analytical method validation, variations control in the preparation of extract, and verification of the accuracy of measurements. The preparation process described in this paper includes steps of material processing, homogeneity testing, stability study, characterization and value assignment [7, 8].

\section{Materials and Methods}

Chemicals and reagents

Potassium chloride standard solution, 1408 $\mu \mathrm{S} / \mathrm{cm}$ prepared according to OIML R56 and IUPAC technical reports[9, 10]. The solution used for quality control procedures and establishing traceability of measurement results. High purity water was obtained through a Milli-Q water purification system used. (Millipore, Bedford, MA, USA) and was used in all procedures.

\section{Equipment}

Conductivity meter with automatic temperature

*Corresponding author email: Tahoun_nis@yahoo.com

Mobile: 00201002644877; Fax/Tel : 0020233867451

DOI: 10.21608/EJCHEM.2018.3005.1254

C2017 National Information and Documentation Center (NIDOC) 
correction (Thermo electron corporation, ORION 4STAR, USA), five digit analytical balance (Sartorius, Germany), shaking machine (Barnstead, USA), waterbath for temperature control(DAIHAN Scientific, KOREA), Whatman filter paper and class A glassware.

\section{Materials Processing and Packaging}

Soil samples were obtained from Al-Fayoum governorate (Al-Fayoum, Egypt).30 kilograms were mixed by shaking and packed in $500 \mathrm{~mL}$ high density polyethylene bottles to prevent humidity uptake, the bottles were stored at room temperature in the dark.

\section{Extraction procedures}

1:5 Ratio [EC $\mathbf{~}_{1: 5}$ ]: Ten grams of air-dry soil sample were accurately weighed and transferred to shaking bottle. $100 \mathrm{~mL}$ of ultra-pure water were added at a temperature of $20 \pm 1{ }^{\circ} \mathrm{C}$. The bottle was closed and placed in a horizontal position in the shaking machine. The samples were shaken for $30 \mathrm{~min}$. then filter directly through a filter paper $[1,6]$. The electrical conductivity of the filtrates was measured by the conductivity meter at a temperature of $25 \pm 0.1^{\circ} \mathrm{C}$.

1:1 Ratio $\left[\mathbf{E C}_{1: 1}\right]_{: 50}$ grams of air-dry soil sample were accurately weighed and transferred to glass beaker. $50 \mathrm{~mL}$ of ultra-pure water were added at a temperature of $20 \pm 1{ }^{\circ} \mathrm{C}$. The suspensions are mixed well with a glass rod, and allowed to stand for 30 minutes. The suspensions were stirred every 10 minutes during this period and after one hour [1, 5]. Then filtered directly through Whatman filter paper. The electrical conductivity of the filtrates was measured by the conductivity meter at a temperature of $25 \pm 0.1{ }^{\circ} \mathrm{C}$.

\section{Homogeneity study}

The homogeneity study was designed to quantify any between bottle heterogeneity of the electrical conductivity values. A total of $10 \%$ of the bottles were selected using random stratified sampling of the whole batch. Five subsamples per bottle were analyzed three times for each sample. All samples were analyzed under repeatability conditions. One way-Analysis of Variance (ANOVA) was used to check the homogeneity of the samples.

\section{Stability study}

Ten bottles were selected randomly for stability study, the bottles were stored at room temperature for $0,2,4,6$ and12 months. Three samples were analyzed in replicates at each time point. The data were checked for outliers and a linear regression analysis as a function of time was performed. Slopes were tested for significance using a $t$ test [8].

\section{$\underline{\text { Results and Discussion }}$}

\section{Results of homogeneity study}

The results of the homogeneity study were analyzed [Fig.1] and uncertainty of the material was estimated and combined with other sources to estimate expanded uncertainty [11-13].

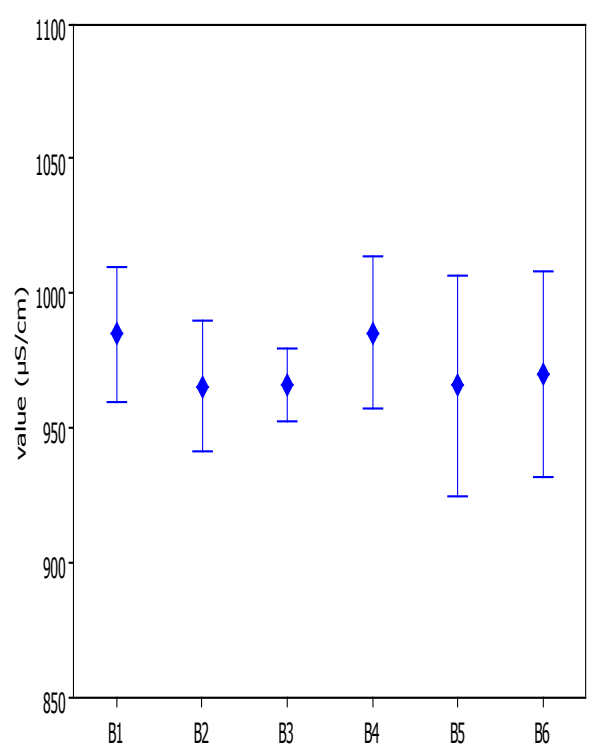

Fig.1. Results of between-bottle homogeneity study of electrical conductivity in soil expressed as $\mu \mathrm{S} / \mathrm{cm}$.

The uncertainty $u_{\mathrm{bb}}$ was estimated from the difference between the total variability and the within bottle variability [8, 14-19] using equation 1 and 2 .

$$
\begin{aligned}
\sigma_{\mathrm{h}}\left(u_{\mathrm{bb}}\right) & =\sqrt{\frac{M S_{\text {between }}-M S_{\text {within }}}{n}} \\
\sigma_{\mathrm{h}}\left(u_{\mathrm{bb}}\right) & =\sqrt{M S_{\text {within }} / n} \cdot \sqrt[4]{2 /\left(v M S_{\text {within }}\right)}
\end{aligned}
$$

In case of $M S_{\text {between }}$ is larger than $M S_{\text {within, }}$, both equations were applied and the largest uncertainty value was selected. The largest uncertainty values were obtained from Eq. (2) because $M S_{\text {between }}$ are 
smaller than $M S_{\text {within }}$ for both methods, which indicates poor repeatability of the measurement method and this is acceptable in measurement of electrical conductivity in soil.

\section{Characterization}

As described in the ISO Guide 35 [8], the property values of reference materials shall be determined by measurement using a single primary method, measurement with two or more independent reference methods, or two additional approaches that involve a network of laboratories, using one or more methods of demonstrable accuracy or also a method-specific approach giving only method-specific assessed property values.

The characterization of the material was conducted using method-specific approach to estimate method-specific values of electrical conductivity. The characterization of the material was based on soil to water ratios, shaking, stirring, agitation, equilibration times and filtration of extracts. The experimental set-up of the characterization study was designed to evaluate EC values and associated variability. For quantitative determination of EC values of the soil material, six bottles were selected from the whole set of 60 bottles and five independent subsamples were measured in five different days using $\mathrm{EC}_{1: 1}$ and $\mathrm{EC}_{1.5}$ methods. Traceability of the measurements results was established by calibrating conductivity meter with potassium chloride standard solution, $1408 \mu \mathrm{S} / \mathrm{cm}$ prepared according to OIML R56 and IUPAC guidelines $[9,10]$ at $20^{\circ} \mathrm{C}$ before analysis. The measurement results of each method (Table 1) were statistically analyzed to test normality and precision. Good reproducibility of data obtained from each method indicate that the study could be continued to produce a fully certified soil reference material.

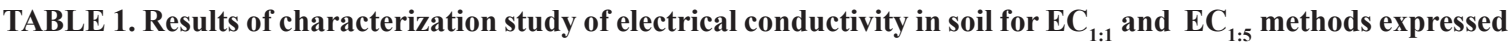
as $\mu \mathrm{S} / \mathrm{cm}$.

\begin{tabular}{ccccccc}
\hline Method & Bottle & Day $\mathbf{1}$ & Day 2 & Day 3 & Day 4 & Day 5 \\
\hline \multirow{5}{*}{ EC $_{1: 1}$} & $\mathrm{~B}_{1}$ & 1211 & 1234 & 1192 & 1275 & 1261 \\
& $\mathrm{~B}_{2}$ & 1200 & 1241 & 1230 & 1260 & 1231 \\
& $\mathrm{~B}_{3}$ & 1240 & 1252 & 1215 & 1235 & 1216 \\
& $\mathrm{~B}_{4}$ & 1255 & 1263 & 1190 & 1248 & 1270 \\
& $\mathrm{~B}_{5}$ & 1272 & 1228 & 1244 & 1231 & 1190 \\
& $\mathrm{~B}_{6}$ & 1261 & 1229 & 1220 & 1247 & 1190 \\
& Average & $\mathbf{1 2 4 0}$ & $\mathbf{1 2 4 1}$ & $\mathbf{1 2 1 5}$ & $\mathbf{1 2 4 9}$ & $\mathbf{1 2 2 6}$ \\
& $\mathrm{S}$ & $\mathbf{2 9}$ & $\mathbf{1 4}$ & $\mathbf{2 1}$ & $\mathbf{1 6}$ & $\mathbf{3 4}$ \\
\hline $\mathrm{B}_{1}$ & 1014 & 953 & 972 & 978 & 982 \\
& $\mathrm{~B}_{2}$ & 970 & 942 & 948 & 995 & 943 \\
& $\mathrm{~B}_{3}$ & 993 & 967 & 969 & 1018 & 927 \\
& $\mathrm{~B}_{4}$ & 963 & 993 & 965 & 957 & 1011 \\
& $\mathrm{~B}_{5}$ & 986 & 974 & 976 & 980 & 967 \\
& $\mathrm{~B}_{6}$ & 938 & 967 & 1008 & 995 & 944 \\
& Average & $\mathbf{9 7 7}$ & $\mathbf{9 6 6}$ & $\mathbf{9 7 3}$ & $\mathbf{9 8 7}$ & $\mathbf{9 6 2}$
\end{tabular}

Results of stability study and assigning material shelf life

Data was plotted as a function of time and the regression line was checked by using a t-test for significant trends possibly indicating change in electrical conductivity values of the material [Fig.2]. The short- and long-term stability results were evaluated regarding absence of outliers in residual plots.
For the short-term stability studies, the results were used to state the maximum time periods allowed for transportation of the material. For the long-term stability studies, the values of uncertainties were calculated as uncertainty of the slope of the regression line $[8,11-13,20]$ and incorporated in expanded uncertainty of the material. The prediction of the material shelf life was based on standard uncertainty due to long 
term stability [8] and uncertainty allowance due to instability was evaluated according to the Eq. 3 .

$$
u_{l t s}=Y_{0} X u_{b}
$$

Where, $\mathrm{Y}_{0}$ is initial value, $\mathrm{X}$ is time point and $u_{b}$ is standard uncertainty due to long term stability

After certification, the reference materials keep on being monitored under storage conditions to maintain confidence in the status of the prepared reference materials.

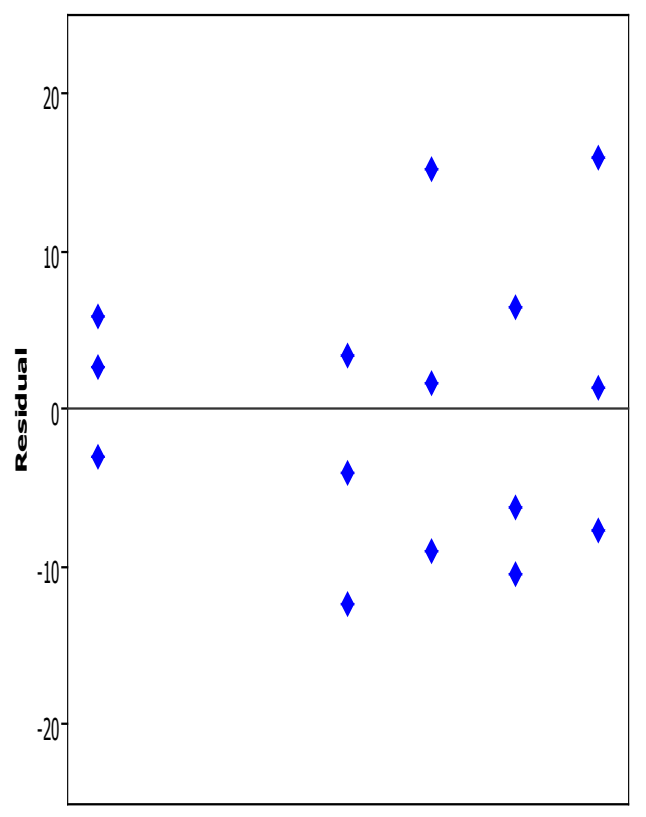

Fig.2. Results of stability study of electrical conductivity in soil expressed as $\mu \mathrm{S} / \mathrm{cm}$.

Value assignment

The certification of the material was performed according to ISO Guides 34:2009 [7] and 35:2006 [8]. The assigned value was calculated as the robust mean from characterization results of each method [7, 21-22]. Kernel density plots were additionally used to identify modes in the measurement results and to confirm assigned value [Fig.3]. Expanded uncertainty is derived from the uncertainty components due to sample inhomogeneity $\left(u_{\mathrm{bb}}\right)$, short term and long term stability $\left(u_{\mathrm{sts}}, u_{l \mathrm{ts}}\right)$ and characterization $\left(u_{\mathrm{char}}\right)$. The uncertainties contributed to characterization include precision $\left(u_{\text {precision }}\right)$ of the analysis (repeatability and reproducibility), uncertainty of standard solution used $\left(u_{\mathrm{CRM}}\right)$ and mass of the samples $\left(u_{\text {sample }}\right)$. Expanded uncertainty is expressed as two times the root of the sum of the squares of $u_{\mathrm{bb}}, u_{\mathrm{sts}}, u_{\mathrm{lts}}$, and $u_{\mathrm{char}}$ at a confidence level of approximately $95 \%$ [23-25], the certified values for $\mathrm{EC}_{1: 1}$ and $\mathrm{EC}_{1: 5}$ methods are $1234 \pm 58 \mu \mathrm{S} / \mathrm{cm}$ and $973 \pm 52 \mu \mathrm{S} / \mathrm{cm}$, respectively.

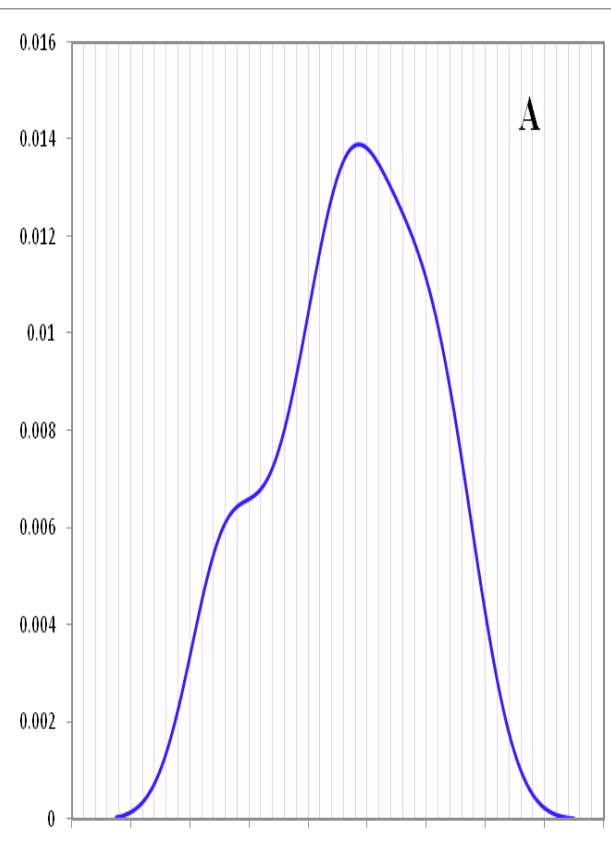

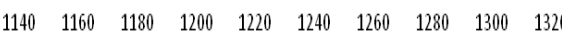

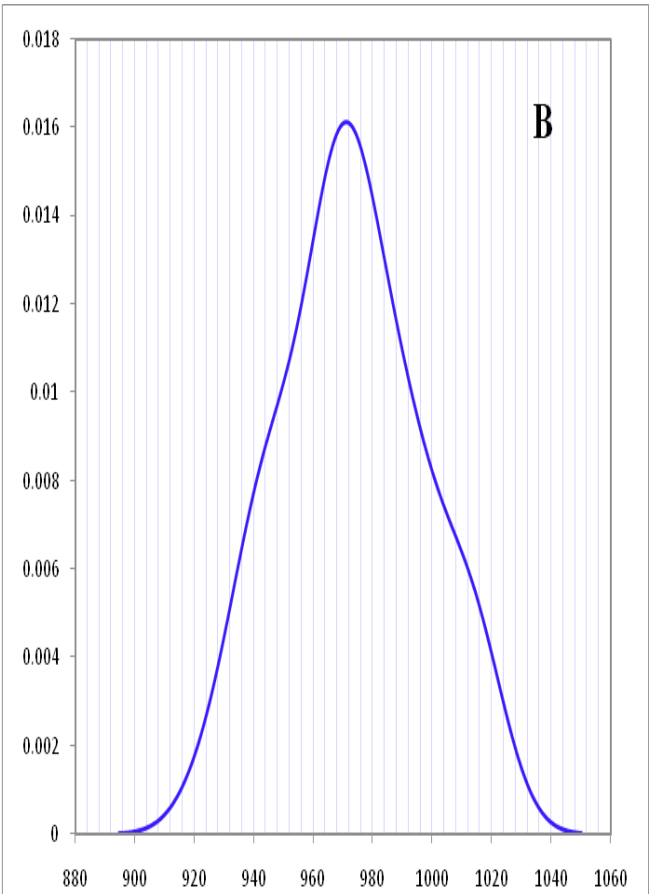

Fig. 3. Kernel density plots for measurement results of EC1:1 (A) and EC1:5 (B) methods

Egypt.J.Chem. 61, No.4 (2018) 


\section{Conclusion}

The certification of electrical conductivity in soil by National Institute of Standards was appropriately concluded. The development of such materials intends to fulfill the strong demand for soil reference materials, due to lack of availability of such materials in the market, the material will be a useful tool for the assurance quality of measurement results, validation of analytical methods and establishing traceability of measurement results to the International System of Units (SI), in order to ensure their accuracy, reliability, and comparability over space and time. Certification was carried out in full compliance with ISO Guides 30-35 and measurement results were statistically treated and the certified values for $\mathrm{EC}_{1: 1}$ and $\mathrm{EC}_{1: 5}$ methods are $1234 \pm 58 \mu \mathrm{S} / \mathrm{cm}$ and $973 \pm 52 \mu \mathrm{S} / \mathrm{cm}$, respectively.

\section{References}

1- USDA, Diagnosis and improvement of saline and alkali soils. Agric. Handbook No.60. , USSL, Riverside, CA, USA. (1954)

2- $\quad$ Rayment G.E. and Higginson F.R., Australian soil and land survey handbook. Australian Laboratory Handbook of Soil and Water Chemical Methods. Inkata Press, Melbourne, Australia (1992).

3- Sumner M.E. and Naidu R., Sodic soils: Distribution, Properties, Management, and Environmental Consequences, Oxford University Press, New York, USA (1998).

4- Rhoades J.D., Manteghi N.A., Shouse P.J. andAlvesW.J., Estimating soil salinity from saturated soil-paste electrical conductivity, Soil Science Society of America Journal, 53, 428-433 (1989).

5- ISO 11265, Determination of the specific electrical conductivity: ISO, Geneva (2016).

6- EstefanG., SommerR., and J. Ryan, Methods of Soil, Plant, and Water Analysis: A manual for the West Asia and North Africa region, -Third Edition- International Center for Agricultural Research in the Dry Areas (ICARDA), Beirut, Lebanon (2013).

7- ISO Guide 34, General requirements for the competence of reference material producers: ISO, Geneva (2009).

8- ISO Guide 35, Reference materials- Guide to general and statistical principles for the certification of reference materials, : ISO, Geneva.
9- OIML R56, Standard solutions reproducing the conductivity of electrolytes, 1981: International Organization of Legal Metrology, France (2006).

10- Pratt K. W., Koch W. F., Y. C. Wu, and Berezansky P. A., Molality-Based Primary Standards of Electrolytic Conductivity, Pure Appl. Chem.,73, 1783-1793(2001).

11- Linsinger T. P. J., Pauwels J., Lamberty A., Schimmel H., van der Veen A.M.H., and Siekmann L., Estimating the uncertainty of stability for matrix CRMs, Fresenius J Anal Chem, 370, 183188 (2001).

12- Development and Use of Reference Materials and Quality Control Materials, IAEA; (2003).

13- Linsinger T. P. J., Pauwels J., van der Veen A.M.H., Schimmel H. and Lamberty A., Homogeneity and stability of reference materials, Accred Qual Assur, 6, 20-26 (2001).

14- Shehata A.B. and Tahoun I.F., Preparation and certification of a fish oil natural matrix reference material for organochlorine pesticides, Accred QualAssur, 15, 563-568 (2010).

15- Shehata A.B., Rizk M.S., Farag A.M. and TahounI.F., Certification of three reference materials for $\alpha$ - and $\gamma$-tocopherol in edible oils, MAPAN-J. Metrol Soc India 29, 183-194 (2014).

16- Shehata A.B., Rizk M.S., Farag A.M. and Tahoun I.F., Development of Two Reference Materials for All trans-retinol, Retinyl palmitate, $\alpha$ - and $\gamma$-Tocopherols in Milk Powder and Infant Formula, J Food Drug Anal, 23, 82-92(2015).

17- Tahoun I.F. and Shehata A.B., Preparation of honey reference material for water content by Karl Fisher and refractometric methods, MAPAN-J. Metrol. Soc. India, 31, 25-29 (2016).

18- Tahoun I.F. and Shehata A.B., Development of Four Parabens Reference Materials Certified for Purity Mass Fraction by Mass Balance Approach, MAPAN- J. Metrol. Soc. India, 31, 145-152(2016).

19- Schiller S.B. and Eberhard K.R., Combining data from independent chemical analysis methods, Spectrochimica Acta B, 46, 1607-1613(1991).

20- Van der Veen A.M.H., Linsinger T.P.J., Lambertyand A and Pauwels J., Uncertainty calculations in the certification of reference materials 3. Stability study, Accred QualAssur, 6, 257-263 (2001). 
21- ISO 5725-1 to 6, Accuracy (trueness and precision) of measurement methods and results: ISO, Geneva (1994).

22- ISO 13528, Statistical methods for use in proficiency testing by interlaboratory comparisons: ISO, Geneva (2015).

23- BIPM, IEC, IFCC, ISO, IUPAC, IUPAP, OIML. Guide to the expression of uncertainty in measurement. 1st ed. Switzerland: ISO: Geneva; 1993. ISBN 92-67-10188-9, corrected and reprinted (1995).
24- Ellison S.L.R. and Williams A. (Eds). Eurachem/ CITAC guide: Quantifying Uncertainty in Analytical Measurement, 3rd Edition, (2012). Available from www.eurachem.org

25- Dobilien J., Meskuotiene A. and Raudien E., Uncertainty sources affecting reliability of chemical measurements, MAPAN-J. MetrolSoc India, 30, 281-290 (2015).

(Received 25/2/2018; accepted 21/6/2018)

\section{تحضير مادة مرجعية لتوكيد جودة نتائج قياسات التوصيلية الكهربية في التربة \\ ابراهيم طاحون، راندا نصر يماني و عادل بسيوني شحاتة

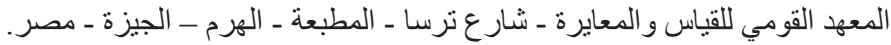

تعتمد جودة نتائج قياس التوصيلية الكهربية للتربة علي القياس بإستخدام طرق تقدير مناسبة مدعومة بطرق تأنأكيد

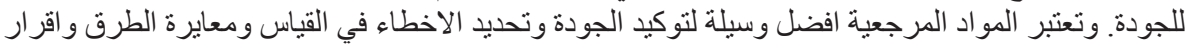

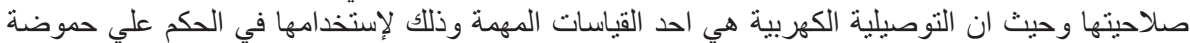

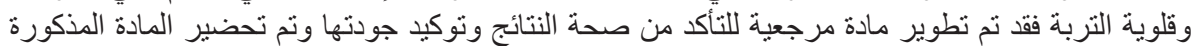

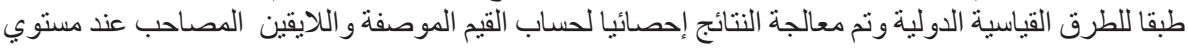

